\title{
0 modo de produção capitalista e a agricultura
}

Oscar Graeff Siqueira ${ }^{1}$

\section{Resumo}

As abordagens teóricas de Marx e de autores marxistas clássicos apresentavam um quadro sombrio de subjugação da agricultura pelo modo de produção capitalista no final do século XIX e início do século XX. Contudo, apesar destas previsões, alguns acontecimentos verificados no final do século XX contrariaram as visões de Marx e seus seguidores, pois a agricultura resistiu à subjugação do capitalismo, obstando a sua dominação completa tanto do ponto de vista produtivo como do social. O exemplo contundente está na sobrevivência do campesinato, classe fadada ao desaparecimento, conforme a abordagem marxista clássica. Ela não só resistiu como se tornou o pilar principal de sustentação agrícola nos países capitalistas centrais. Sua denominação pode variar conforme o país, mas é conhecida como agricultura familiar ou pequena unidade de produção familiar.

Palavras-chave: Modo de Produção Capitalista. Campesinato. Agricultura Familiar.

\begin{abstract}
The theoretical approaches of Marx and Marxist classics authors presented a grim picture of subjugation of agriculture by the capitalist mode of production in the late nineteenth century and early twentieth century. However, despite these predictions some events occurring in the late twentieth century contradicted the views of Marx and his followers, because agriculture resisted the subjugation of capitalism, while preventing its complete dominance of both the productive point of view as the social. The striking example is the survival of the peasantry, doomed to disappear as the classical Marxist approach to class. It not only endured as it has become the mainstay of agricultural support in the core capitalist countries. His name may vary by country, but is known as family farming or small unit of family production.
\end{abstract}

Keywords: The capitalist production mode. Peasant. Family farming.

\footnotetext{
${ }^{1}$ Mestre em Desenvolvimento Rural pelo PPGDR/UFRGS. portopartida@yahoo.com.br 


\section{Introdução}

A agricultura e os diversos setores sociais que a compõem, suas relações entre si e os demais setores e segmentos da sociedade industrial capitalista suscitaram, no início do século XIX, um intenso e instigante debate sobre os rumos e os comportamentos esperados da agricultura e de seus diversos agentes sociais. Esse debate produziu uma gama enorme de teorias sobre como o modo de produção capitalista, através do processo de transformação da matéria-prima em produto industrializado, passaria a relacionarse com a agricultura, influenciando e modificando-a. Ou seja, sendo modificada em suas características originais, passando a ser algo novo, mas trazendo consigo uma agregação de valor e de fatores de produção, como trabalho e capital, se tornando o resultado final de um modo de produção, um produto. Os diversos autores que se propuseram a diagnosticar e a projetar os destinos da agricultura, principalmente os autores clássicos, como Marx, Kautsky, Lênin e outros, elaboraram uma série de hipóteses relacionadas às modificações que seriam introduzidas na agricultura e nos seus segmentos sociais, pelo modo de produção capitalista. As modificações ocorreriam através da industrialização da agricultura, com sua efetiva submissão ao capitalismo, com o desaparecimento de classes e categorias sociais, e o surgimento de novas, decorrentes do processo de penetração do sistema capitalista e suas relações produtivas e sociais na agricultura.

Entretanto, o transcorrer do tempo e o desenvolvimento do modo de produção capitalista trouxeram à tona, para o debate contemporâneo, uma série de constatações que, ao mesmo tempo, afirmaram a introdução do modo de produção capitalista na agricultura, e outras que derrubaram conceitualizações clássicas sobre a penetração do capitalismo na agricultura e sobre o destino de seus agentes sociais. Isso propiciou o surgimento de um certo paradoxo entre os diversos autores, clássicos e contemporâneos, pois o aparecimento de novas categorias explicativas colocou em xeque categorias anteriores que balizaram, durante muito tempo, o debate sobre o modo de produção capitalista e suas relações com a agricultura.

O objetivo deste artigo é o de, através de uma abordagem qualitativa e não quantitativa, fazer um breve debate entre os diversos autores clássicos e contemporâneos, a fim de suscitar a discussão sobre a concretização de argumentos teóricos, que nem sempre têm sua confirmação pela realidade objetiva. As teorias elaboradas pelos pensadores clássicos tinham, no seu íntimo, muito do cunho determinístico e racional sobre o comportamento das classes sociais do campo, algo que, até o momento, não foi confirmado pela realidade contemporânea. Assim, este trabalho procura debater e problematizar sobre este tema extremamente provocador, que se refere às relações e aos possíveis laços de ligação entre o modo de produção capitalista e a agricultura.

\section{As abordagens clássicas}

\subsection{A penetração do capitalismo na agricultura}

Para Marx, apud Silva (1996), um elemento fundamental do desenvolvimento do capitalismo era a criação do mercado interno, ou seja, o desenvolvimento da produção mercan- 
til, através da divisão social do trabalho, onde a penetração deste na agricultura apoiavase na separação dos diferentes processos de transformação das matérias-primas, que eram retiradas, uma a uma, da agricultura, para, posteriormente, transformarem-se em ramos industriais com vida própria, retornando a relacionar-se com a agricultura, através da venda de mercadorias, trocando seus produtos por produtos agrícolas. Assim, a agricultura se transformaria em indústria, através de um semelhante processo de especialização, produzindo mercadorias, como ocorre na indústria.

Outro autor clássico, Kautsky, também afirmava que a agricultura seria subjugada pela indústria, deixando a primeira de ter um papel destacado no processo de transformação da sociedade, corroborando, assim, com a visão de Marx sobre o processo de industrialização da agricultura.

Na mesma direção, Lênin, apud Silva (1996), destacou que, através da ampliação da divisão social do trabalho na sociedade, os mercados iriam sendo criados, levando ao desenvolvimento do capitalismo, portanto não necessitando a priori de um mercado interno, pois, neste processo, era importante o crescimento do consumo dos bens intermediários, necessários à expansão da produção capitalista.

Dessa forma, apesar de algumas divergências entre a abordagem de Marx e de Lênin, ambos concordavam com a ideia de que o princípio fundamental da penetração do modo de produção capitalista na agricultura dava-se através do aprofundamento da divisão social do trabalho, onde, a partir da proletarização do camponês e da destruição de sua economia natural, seriam criadas as bases para o desenvolvimento do modo de produção capitalista na agricultura. A proletarização do camponês baseava-se na visão clássica, desenvolvida por Marx, sobre a questão da renda fundiária, que será abordada mais adiante neste artigo, segundo a qual existiriam três figuras clássicas no capitalismo agrário propriamente dito (FREITAS; ALMEIDA; CABRAL, 1976), que eram o proprietário fundiário (landlord), o capitalista arrendatário (farmer) e o trabalhador rural sem terra, que se constituía no proletário rural ou "semi-proletário" (termo cunhado por Lênin, sobre os trabalhadores rurais na Rússia, no início do século XX), semelhante ao proletário ou operário urbano.

De acordo com Marx, o ponto principal do processo da divisão social do trabaIho, que era desenvolvido e elaborado através da troca de mercadorias, era a separação entre o campo e a cidade, onde o modo de produção capitalista completava a ruptura dos laços primitivos, que, no começo, uniam a agricultura e a manufatura, criando, ao mesmo tempo, as condições materiais para uma nova síntese, superior, para unir a agricultura à indústria, em bases estruturais que se construíram em oposição mútua.

Assim, a separação campo-cidade se constituiria, na verdade, na maneira como o modo de produção capitalista se desenvolveria na agricultura. Dentre os vários exemplos, poder-se-ia citar o ocorrido com o artesanato doméstico, que era uma atividade complementar das famílias camponesas e que foi destruído pelo desenvolvimento do mercado interno capitalista, quebrando a harmonia existente entre Homem-Natureza, para depois recriá-la, agora não mais baseada nas condições naturais, mas em condições fabricadas, produzidas pelo próprio homem.

Portanto, para Marx, esta separação era a ocorrência de dois processos: um de destruição da economia natural, através da retirada progressiva dos vários componentes 
que asseguravam a harmonia da produção assentada na relação Homem-Natureza; e o outro, de uma nova síntese, recomposta noutra harmonia, baseada no conhecimento e controle cada vez maior da Natureza e na possibilidade da reprodução artificial das condições naturais da produção agrícola, denominando-se industrialização da agricultura.

Esta separação campo-cidade somente se completaria, quando a indústria se transferisse para a cidade, e a reunificação, quando o próprio campo se convertesse numa fábrica, o que revelava que a agricultura entendida como um setor autônomo desapareceria, convertendo-se num ramo da própria indústria, através de um longo processo de transformação de sua base técnica - modernização - culminando na própria industrialização da agricultura (SILVA, 1996).

Dessa forma, o processo de subordinação da Natureza ao capital, libertaria o processo de produção agropecuária das condições naturais dadas, passando a fabricá-las sempre que se fizessem necessárias. Assim, onde faltasse chuva, irrigar-se-ia; na falta de fertilidade do solo, adubava-se; se houvesse incidência de doenças e pragas, usar-se-ia defensivos químicos ou biológicos, e assim por diante. Porém, o que merece ser destacado é que a produção agropecuária estaria deixando de ocorrer ao sabor das forças da Natureza, para ser industrializada, tornando-se um setor subordinado ao capital, devidamente integrado à grande produção industrial (SILVA, 1996).

\subsection{A agricultura no capitalismo e a configuração das classes sociais}

A penetração do modo de produção capitalista na agricultura, através da sua industrialização, traria sérias consequências na configuração das classes e categorias sociais, no campo e nas relações fundiárias, ou seja, da propriedade da terra. De acordo com Marx, não haveria mais espaço, dentro do capitalismo, notadamente na agricultura, para a pequena propriedade camponesa, pois esta, segundo ele, estaria fadada ao desaparecimento, devido ao desenvolvimento do modo de produção capitalista no campo, restando espaço somente à grande propriedade produtora capitalista, a qual teria condições de investir significativamente, obtendo uma elevada lucratividade devido aos ganhos decorrentes de uma escala maior de produção.

Marx, apud Freitas, Almeida e Cabral (1976), baseou sua análise das classes sociais que restariam na agricultura, no estudo do caso Inglês, ou seja, no modelo social vigente na Inglaterra, o qual denominou como a composição clássica para a constituição das classes e categorias sociais no capitalismo agrário, com apenas três classes assim configuradas: o dono da terra ou proprietário fundiário (landlord); o arrendatário capitalista (farmer) e o trabalhador ou operário rural sem terra, que se assemelhava ao proletário urbano.

Conforme já citado anteriormente, estas classes constituíam-se no que Marx designava como as resultantes do processo de industrialização da agricultura, pois a figura do pequeno produtor camponês estaria fadada a desaparecer. Para Marx, o modo de produção do pequeno camponês constituía-se numa forma pré-capitalista, que não teria espaço no mundo capitalista.

A sociedade capitalista, na concepção de Marx, seria o desenvolvimento da contradição entre o caráter privado e social do trabalho, objetivando a preparação 
para uma organização social racionalmente disposta e controlada, com um duplo caráter da própria socialidade no mundo das mercadorias, reduzindo-se a apenas duas classes em luta para a formação de um mundo novo: a burguesia e o proletariado (ABRAMOVAY, 1992).

Desse modo, conforme Marx, com o desenvolvimento do capitalismo, o qual distribuía várias funções entre diferentes pessoas, nada mais lógico que o artesão ou o camponês, quando mencionados, que produziam, com seus próprios meios de produção, aparecessem como espécies condenadas fatalmente à diferenciação, e, por conseguinte, à eliminação social, pois, ou seriam transformados gradualmente em pequenos capitalistas, que explorariam o trabalho alheio, ou perderiam seus meios de produção, transformando-se, assim, em trabalhadores assalariados (ABRAMOVAY, 1992).

Foi nesse sentido que Marx, então, expressou que as duas únicas classes que possuíam a universalidade de incorporar nelas mesmas os aspectos básicos de organização da socialidade contemporânea seriam a burguesia e o proletariado.

\subsection{A renda da terra}

A busca do capitalista, no processo produtivo, de um valor que cubra os seus custos de produção, agregando-Ihe um valor extra, valorizando, assim, o seu capital investido, ocorre através do ganho adicional denominado lucro. Marx, ao analisar a penetração do capitalismo na agricultura, observou que, através da configuração das classes sociais citadas anteriormente, que se constituíam na forma modelar e clássica de organização social no capitalismo agrário, a obtenção do lucro pelo capital se daria na forma de uma renda fundiária decorrente do monopólio da terra e na extração de mais-valia do trabalhador rural, tanto pelo capitalista arrendatário como pelo proprietário fundiário, sendo que, para este último, o processo de extração de mais-valia seria de forma indireta, pois esta estaria embutida no preço do arrendamento pago pelo capitalista ao dono da terra.

No entanto, de acordo com Marx, apud Silva (1981), na agricultura, haveria uma situação ímpar, pois, em decorrência da terra ser um bem imóvel de propriedade privada, esta se constituía num monopólio que era utilizado pelos proprietários rurais ao seu bel prazer, gerando-Ihes, devido a essa situação, uma renda fundiária, e, por conseguinte, um sobrelucro permanente, diferentemente da indústria, em razão do monopólio da propriedade privada da terra.

Segundo Marx, a simples propriedade jurídica da terra não gerava renda, entretanto esse monopólio da terra poderia assumir dois aspectos distintos, pois, de um lado, o monopólio de uma determinada área de terra com fins econômicos, onde o capitalista estivesse cultivando um pedaço do solo com certas características de fertilidade, de localização e de benfeitorias já incorporadas ao solo, como valas de irrigação e drenagem e outras; e, de outro lado, o monopólio da propriedade privada da terra em si mesmo, a partir do qual algumas poucas pessoas possuíam o direito de uma parcela do globo terrestre e poderiam dispor dela como bem quisessem; levando o monopólio da terra a assumir um duplo aspecto que permitiria distinguir 
dois tipos de renda da terra: $a$ absoluta ${ }^{2}$ e a diferencial ${ }^{3}$.

A renda diferencial consistia no lucro extraordinário, obtido pelos capitais aplicados na produção agrícola, acima do lucro médio, podendo ser classificada como renda diferencial I - fração "natural", oriunda das diferenças de localização em relação aos mercados, e de fertilidade, inerentes aos tipos de solos; e renda diferencial II - fração "fabricada" pelos investimentos adicionais (meios de produção e trabalho) numa mesma área de terra.

Outro aspecto importante a ser destacado, conforme Marx, apud Silva (1981), referia-se à condição que representava a renda diferencial. Ela representaria sempre uma diferença nos preços de produção em relação ao pior solo cultivado - em termos de localização e de fertilidade - concluindo-se, a partir daí, que, neste último, a renda diferencial seria nula, o que não significava que a exploração seria gratuita, pois, do contrário, o monopólio da terra, exercido pela classe dos proprietários, não teria sentido. Sendo assim, o monopólio da propriedade privada da terra constituía-se tão somente na condição necessária, porém não suficiente, à existência da renda terra, seja ela absoluta ou diferencial, erguendo-se, entretanto, como uma barreira ao capital, pois, sem o monopólio, o lucro suplementar, no caso da renda diferencial, não se converteria em renda, e caberia ao arrendatário capitalista, e não ao proprietário fundiário. Esta barreira continuaria a existir, mesmo com o desaparecimento da renda diferencial, ou seja, na área com o pior solo.

\subsection{Subsunção formal e real}

Além da questão relativa à renda da terra, segundo Marx, a penetração do modo de produção capitalista na agricultura, através da industrialização da agricultura, ocorreria dentro de um processo de aprimoramento dos meios técnicos e científicos: o surgimento de novas máquinas e equipamentos, além de novos fertilizantes e adubos químicos, e outros novos produtos ligados à física e à química, promoveriam a expansão da produção e da produtividade agrícola, subordinando as forças da natureza ao capital, através do progresso da aplicação tecnológica da ciência e da sua incorporação ao processo produtivo.

\footnotetext{
${ }^{2}$ Renda absoluta consistia no valor pago pelo capitalista arrendatário ao proprietário fundiário, decorrente da propriedade privada e do monopólio exercido por este último em relação a terra, porém, desde que a composição orgânica do capital, aplicada na agricultura, fosse inferior à do capital social médio. Portanto, onde a quantidade de capital constante, ou seja, a parte do capital total que apenas transferia seu valor para as mercadorias, sem criar mais-valia, materializada através dos meios de produção: máquinas, equipamentos e outros, não fosse mais elevada em relação ao capital variável, representado pela parte do capital total que extraía a mais-valia através da compra da força de trabalho (BOTTOMORE, 1988).

${ }^{3}$ Renda diferencial da terra, de acordo com Marx, era gerada pelo monopólio relativo à sua utilização e à sua exploração, decorrente do fato de que a terra, como meio de produção, não era homogênea, sendo limitada na sua extensão e, de certa maneira, não reprodutível, constituindose num monopólio privado na sociedade capitalista. Em decorrência desse monopólio, o preço de mercado de um produto agrícola qualquer acabava sendo determinado em função do preço de produção referente à pior terra cultivada - necessária para satisfazer a demanda global - e não pela média, pois, se não fosse assim, os produtores localizados nas terras menos produtivas não conseguiriam obter sequer o lucro médio (BOTTOMORE, 1988).
} 
Dessa forma, o progresso das técnicas de produção representaria, antes de qualquer coisa, um progresso das técnicas capitalistas de produção, dentro do processo de valorização do capital. Assim, todo o progresso técnico estaria relacionado com o aumento da produção e da produtividade do trabalho, promovendo uma maior eficiência da força produtiva do trabalho, objetivando, conforme Marx, a submissão do trabalho ao capital no modo de produção capitalista.

Essa submissão ou subordinação do trabalho ao capital, segundo Marx, apud Silva (1981), que existia na subordinação indireta (capital comercial e usurário), sob a forma de dinheiro, existia na subordinação direta (formal e real), no processo de produção, consistindo numa autovalorização do capital, através do processo de produção que geraria mais-valia.

Para Marx (1994), a força de trabalho em atividade não só reproduzia seu próprio valor, mas também criava valor excedente. Esse valor excedente, ou mais-valia, constituía o excedente do valor do produto em relação ao valor dos componentes dos produtos consumidos, a saber, os meios de produção e a força de trabalho. Ao discorrer sobre os diversos papéis que os diferentes fatores do processo de trabalho desempenhavam na formação do valor do produto, na realidade, Marx caracterizava as funções dos diversos componentes do capital no processo de produzir mais-valia.

Segundo o mesmo autor, o excedente que o valor total do produto teria sobre a soma dos valores de seus elementos constitutivos era o excedente do capital ampliado sobre o capital originalmente despendido, e os meios de produção, de um lado, e a força do trabalho, de outro, seriam apenas diferentes formas de existência, assumidas pelo valor do capital original ao despir-se da forma dinheiro e transformar-se nos fatores do processo de trabalho. Portanto, conforme Marx (1994), a parte do capital que se convertia em meios de produção, isto é, em matéria-prima, materiais acessórios e meios de trabalho, não mudava a magnitude do seu valor no processo de produção, sendo por ele chamada de parte constante do capital ou simplesmente capital constante.

A parte do capital convertida em força de trabalho, ao contrário, mudava de valor no processo de produção, reproduzindo o próprio equivalente e, além disso, proporcionava um excedente, a mais-valia, que poderia variar, ser maior ou menor. Essa parte do capital transformava-se, continuamente, de magnitude constante para magnitude variável, chamando-se parte variável do capital, ou, simplesmente, capital variável. As mesmas partes do capital que, do ponto de vista do processo de trabalho, se distinguiam como elementos objetivos em meios de produção e força de trabalho, do ponto de vista do processo de produzir mais-valia, se distinguiam como capital constante e capital variável (MARX, 1994).

Desse modo, Marx (1994) chamou de mais-valia absoluta a produzida pelo prolongamento do dia de trabalho, e de mais-valia relativa a decorrente da contração do tempo de trabalho necessário e da correspondente alteração na relação quantitativa entre ambas as partes componentes da jornada de trabalho, ou seja, alteração entre a relação de capital constante e capital variável. Para este mesmo autor, a mais-valia, fosse absoluta ou relativa, constituía um fundo de consumo individual do capitalista, pois era o produto excedente da produção, também considerado como um fundo de acumulação. Entretanto, na verdade, a mais-valia constituía-se em ambas as coisas, pois uma parte 
dela era consumida como renda do capitalista, e a outra parte era empregada como capital ou acumulada.

Dada uma certa quantidade de mais-valia, uma dessas partes seria tanto maior quanto menor fosse a outra; portanto, permanecendo iguais as demais circunstâncias, a proporção existente entre essas partes seria a determinante da magnitude da acumulação. Porém, o realizador dessa divisão era o proprietário da mais-valia, o capitalista, que praticava, assim, um ato de vontade, sendo que a parte por ele acumulada era economizada, ou seja, não consumida, porque estava exercendo sua função de capitalista, a de enriquecer (MARX, 1994).

O processo de valorização do capital, através da extração de mais-valia, recorrendo ao prolongamento do tempo de trabalho, extraindo a mais-valia absoluta, foi denominado por Marx como subsunção formal do trabalho ao capital. Neste estágio do processo de trabalho, este não sofreria ainda uma transformação fundamental, do ponto de vista tecnológico, devido ao aspecto essencial da subsunção formal restringir-se a uma relação puramente monetária na apropriação do sobretrabalho.

Porém, quando o modo de produção capitalista desenvolvesse as suas próprias bases, inclusive a tecnológica, alterando significativamente o processo de trabalho, ocorreria a subsunção real do trabalho ao capital, expressada numa forma mais desenvolvida da produção denominada de mais-valia relativa.

A maneira de como seria produzida a mais-valia relativa foi descrita por Marx através da cooperação baseada na divisão do trabalho, por meio da qual os trabalhadores executavam diferentes tarefas que se encadeavam e se complementavam; da divisão do trabalho propriamente dita e da introdução de máquinas e equipamentos no processo produtivo, ilustrando, dessa forma, a passagem da subsunção formal à subsunção real.

Dada toda esta configuração a respeito das classes sociais, que, na visão de Marx, consistiam na base modelar da organização do modo de produção capitalista na agricultura - abordagem clássica - mais os processos relacionados à obtenção da renda da terra e à extração de mais-valia, através da subsunção formal e real do trabalho ao capital, ele procurou indicar que as relações sociais e produtivas na agricultura, com a introdução do capitalismo no campo, sofreriam profundas e significativas alterações. Estas levariam ao desaparecimento da pequena unidade produtora camponesa, dando lugar à grande exploração capitalista, já que somente esta última teria as condições objetivas de garantir sua reprodução social, pois conseguiria concentrar em suas mãos o capital e o monopólio dos meios de produção, e, dentre eles, evidentemente, o da terra.

Sendo assim, Marx afirmava que o destino do camponês e de sua família seria o da proletarização, tornando-se um trabalhador assalariado, rural ou urbano, desprovido de seus meios de produção e de subsistência, passando única e exclusivamente a depender da venda de sua força de trabalho, para garantir a sua sobrevivência e a de sua família.

\subsection{As abordagens de Lênin e Kautsky}

Lênin (1988) também afirmava ser este o destino do campesinato, ao analisar o caso dos camponeses russos e do monopólio da propriedade das terras, que se con- 
centrava nas mãos dos latifundiários (na sua grande maioria, nobres) e dos camponeses ricos, apesar a existência da MIR (uma comunidade territorial com governo próprio, de caráter comunitário de acesso a terra, onde este governo territorial era o proprietário legal das terras), pois, conforme o autor, os ricos buscavam, cada vez mais, alianças com os latifundiários, em detrimento dos camponeses mais pobres.

Em razão disso, Lênin (1988) destacou a necessidade dos camponeses pobres não se deixarem iludir por falsos discursos de que a propriedade da terra lhes garantiria a sobrevivência, pois somente os nobres e os camponeses ricos tinham condições econômicas e financeiras de sobreviver no campo. O aprofundamento constante das relações do modo de produção capitalista na agricultura levaria à exclusão do pequeno camponês do processo produtivo, dissociando-o de seus meios de produção, principalmente de sua terra, transformando-o, no médio e no longo prazo, em trabalhador assalariado - semi -proletário -, próximo ao proletário urbano.

Outro autor clássico, Kautsky (1968), ressaltou que a agricultura seria subjugada pela indústria, dentro do processo de expansão do modo de produção capitalista, pois deixaria de ter papel destacado nesse tipo de sociedade, tornando-se uma extensão ou um ramo do setor industrial. Ele observou que haveria, na agricultura, a possibilidade da existência de duas formas de produção, uma pré-capitalista e outra capitalista, sendo a primeira caracterizada pela pequena exploração camponesa, e a segunda, pela grande propriedade exploradora, onde haveria os grandes produtores e os proletários rurais.

Para Kautsky (1968), as idéias de Marx, tais quais elas eram em relação ao destino dos pequenos camponeses e da completa industrialização da agricultura, tenderiam a não se confirmar na sua totalidade. Apesar disso, ele concordava com Marx que a grande exploração capitalista seria a preponderante nas atividades de produção agrícola, pois o modo de produção capitalista teria que conviver com formas de produção précapitalistas na agricultura, que se baseavam, principalmente, na pequena propriedade camponesa.

Entretanto, Kautsky (1968) ressaltou que, quanto maior fosse o progresso do capitalismo na agricultura, mais se acentuaria a diferença qualitativa entre as técnicas de produção da grande exploração agrícola em relação à pequena exploração agrícola. A grande exploração agrícola, dessa maneira, teria maiores ganhos de escala, pois conseguiria empregar mais máquinas, equipamentos e fertilizantes na produção agrícola, habilitando-se, também, de forma mais racional, ao processo de divisão social do trabalho, algo que estaria descartado à pequena exploração agrícola, devido esta não possuir as condições econômicas e financeiras necessárias para a realização deste processo em seu espaço produtivo.

Portanto, conforme o autor acima, a pequena exploração camponesa estaria condenada a permanecer apenas como um apêndice da grande exploração capitalista, pois a primeira contribuiria com a segunda no fornecimento de produtos complementares, que não estariam incluídos no circuito de comercialização de grande lucratividade, onde estariam os produtos originários das grandes explorações capitalistas; e, ainda, serviria como fonte de oferta de mão-de-obra às grandes explorações capitalistas, que teriam, assim, em parte, sua reprodução assegurada, desde que houvesse uma oferta abundante de mão-de-obra camponesa, originária da pequena exploração agrícola. 
Nessa altura, pode-se verificar, na abordagem de Kaustsky (1968), uma mudança qualitativa importante, quando o autor, um marxista clássico, muda significativamente o enfoque de Marx, ao admitir que a pequena exploração camponesa não seria totalmente extinta, e que nem todos os camponeses estariam condenados à completa proletarização, conforme afirmara Marx. Porém, Kaustsky fez questão de enfatizar a superioridade da grande exploração capitalista em relação à pequena exploração camponesa, pois, nesta última, a sobrevivência do camponês e de sua família se daria de forma extremamente precária, experimentando estas condições agudas de miséria e privações de todas as espécies.

\subsection{O campesinato de Alexander Chayanov}

Dentro deste ambiente, caracterizado pelo debate entre os autores clássicos Marx e seus seguidores - sobre a penetração do modo de produção capitalista na agricultura e as alterações sociais e produtivas que seriam promovidas com a introdução do capitalismo no campo, onde, em tese, ocorreria a preponderância de grande exploração capitalista agrícola, em detrimento da pequena unidade produtiva camponesa, transformando o camponês e sua família em trabalhadores assalariados, tem destaque a obra de Alexander Chayanov (1888-1930), com a sua abordagem sobre a questão camponesa, conforme Abramovay (1992), não só por ser professor de um importante instituto de agronomia perto de Moscou, mas pela relevância de suas publicações.

Chayanov foi o principal expoente de um grupo de economistas agrícolas e engenheiros agrônomos que ficou conhecido como Escola da Organização da Produção, por sua permanente tentativa de contribuir para que os camponeses pudessem melhor gerir os seus recursos disponíveis. Este grupo, na verdade, exprimia o trabalho molecular realizado por milhares de jovens agrônomos, no interior da Rússia, que reuniram seu sentimento de oposição ao tzarismo em pesquisas extremamente minuciosas sobre a vida camponesa. Além de um profundo conhecimento da geografia agrária de seu país, Chayanov era um estudioso dos assuntos ligados ao desenvolvimento agrícola e, sobretudo, do cooperativismo na França, Suíça, Itália, Alemanha e Bélgica, onde manteve contatos com outros importantes intelectuais (ABRAMOVAY, 1992).

Alexander Chayanov era um opositor contunde da coletivização das propriedades, pois entendia que as propriedades camponesas, organizadas na MIR, não caracterizavam propriedades de cunho capitalista; portanto, não seria necessária sua coletivização. Ao atribuir à propriedade camponesa um caráter não capitalista, Chayanov buscava também uma abordagem alternativa à visão marxista, que enxergava o camponês como uma espécie de ornitorrinco social (simultaneamente patrão, empregado, proprietário e arrendatário de si próprio) o que parecia mais um recurso de linguagem que um instrumento para se compreender de fato aquilo que Chayanov considerava como objeto de conhecimento necessário e possível, ou seja, a morfologia da máquina produtiva chamada unidade de produção camponesa.

Conforme Abramovay (1992), Chayanov, em seu empreendimento teórico, buscava elaborar uma Teoria dos Sistemas Econômicos Não Capitalistas, onde, é claro, destacar-se-ia a economia camponesa, pois o campesinato não se configurava apenas numa 
forma ocasional, transitória, fadada ao desaparecimento, mas, ao contrário, mais que um setor social, tratava-se de um sistema econômico, com leis próprias de reprodução e de desenvolvimento, contrapondo-se às escolas econômicas marxistas e neoclássicas ${ }^{4}$.

A comunidade camponesa destacada por Chayanov baseava-se no processo de organização social das comunidades camponesas russas (MIR), onde havia uma comunidade territorial com governo próprio e que era a principal proprietária legal das terras possuídas ou utilizadas por suas unidades domésticas. Tratava-se de uma unidade administrativa local, responsável por uma série de poderes e tarefas dentro de cada comunidade camponesa.

De caráter eletivo, era normalmente dominada pelos camponeses mais ricos e governada pelos anciãos da comunidade. Cada família detinha, em regime de propriedade privada (e passível de transmissão por herança), apenas um pequeno lote, sendo a área restante distribuída por este conselho comunitário, levando-se em consideração o tamanho da família; portanto, sua capacidade de trabalho e suas necessidades de consumo. A forma de distribuição da terra com base no tamanho da família era considerada fundamental por Chayanov, pois privilegiava parte das terras para serem trabalhadas coletivamente (ABRAMOVAY, 1992).

A economia camponesa de Chayanov tinha suas ideias organizacionais, através da maquinaria de seu organismo econômico individual, que era a unidade subjetiva teleológica da atividade econômica racional, isto é, da gestão de seu estabelecimento. Não era o estudo de sua inserção na divisão social do trabalho e o papel que ele aí desempenhava que explicariam o comportamento camponês: ao contrário, era pelo estudo de seu comportamento que se poderia compreender a maneira como ele, enquanto unidade subjetiva teleológica, inseria-se socialmente.

A lei básica da existência camponesa poderia ser resumida na expressão balanço entre trabalho e consumo, cujo principal objetivo econômico era organizar o ano de trabalho, para atender a demanda da família, até mesmo o desejo de poupar ou investir capital, se possível. Num estabelecimento camponês, o critério de maximização da utilidade não era a obtenção da maior lucratividade possível em determinadas condições, pois o uso do trabalho camponês seria limitado pelo objetivo fundamental de satisfazer as necessidades familiares (ABRAMOVAY, 1992).

Desse modo, a renda familiar era um todo indivisível, cuja formação se originava e dependia de um organismo econômico único. O que determinava o comportamento do camponês não seria o interesse de cada um dos indivíduos que compõem a família, mas sim as necessidades decorrentes da reprodução do conjunto familiar, o que Chayanov chamou de autoexploração do campesinato, fundamentalmente pela razão entre a penosidade dos esforços empreendidos, relativamente à satisfação de suas necessidades (ABRAMOVAY, 1992).

A determinação do comportamento camponês por uma dinâmica destacadamen-

\footnotetext{
${ }^{4}$ A Escola Neoclássica foi a escola de pensamento econômico predominante entre 1870 e a Primeira Guerra Mundial, também conhecida como escola marginalista, por fundamentar-se na teoria subjetiva do valor da utilidade marginal, para reelaborar a teoria econômica clássica. Caracterizava-se fundamentalmente por ser microeconômica, baseada no comportamento dos indivíduos e nas condições de um equilíbrio estático, estudando os grandes agregados econômicos, a partir desse ponto de vista, e com o uso da matemática (SANDRONI, 1994).
} 
te interna à família não significava que esta se isolava socialmente, produzindo para a subsistência, sem passar pelo mercado, estranha aos mecanismos de tomada de financiamento ou avessa ao progresso técnico. Assim, se o investimento de capital significasse gasto de dinheiro, visando à redução de esforços, sem que isso se traduzisse em aumento da renda bruta da família, ou de maneira a provocar uma ociosidade do trabalho, cuja utilização teria a virtude igualmente de aumentar a renda bruta, sem, entretanto, provocar gastos com compras de equipamentos, a inversão não seria feita.

\section{A abordagem contemporânea}

\subsection{A supremacia da agricultura familiar}

Ao trazer o debate para os dias atuais, verifica-se que muitas das previsões efetuadas sobre o destino do campesinato e de sua pequena unidade de produção não se confirmaram. Muitas características levantadas e atribuídas a esta classe não se configuraram, ou sofreram alterações significativas, o que é expresso inicialmente na abordagem de Veiga (1991), na qual o autor ressalta que, ao contrário do que se previa, principalmente nas visões de Marx, Lênin e Kautsky, a classe camponesa não desapareceu, porém sofreu mutações significativas nas suas relações produtivas e sociais, constituindo-se na base da produção agrícola nos países capitalistas centrais.

A necessidade de comida farta e barata levou os governos dos países capitalistas centrais a incitar a expansão da produção agrícola através de um ritmo de progresso tecnológico sem precedentes. As políticas agrícolas passaram a combater os fatores de instabilidade e incerteza, procurando compatibilizar a necessidade de reduzir gradualmente os preços alimentares ao consumidor com a necessidade de garantir um nível aceitável de vida aos agricultores (VEIGA, 1994). Estas políticas foram adotadas nos Estados Unidos, através do controle na expansão das áreas de cultivo e na oferta de produção agrícola, por meio da intervenção do Estado. As políticas de controle de produção e de fixação de preços garantiram o abastecimento dos produtos agrícolas ao consumidor a preços baratos e mantiveram a renda dos agricultores.

Na Europa, através da Comunidade Econômica Europeia - CEE (atual União Europeia), através da adoção da Política Agrícola Comum - PAC, os Estados congregados em uma entidade supranacional procederam a intervenções, principalmente nas políticas de preços - preços de intervenção -, procurando garantir o farto abastecimento alimentar de suas populações a preços baratos e a manutenção da renda dos produtores agrícolas. Isso levou a Europa, no início dos anos 1980, a tornar-se excedentária na produção agrícola (FONSECA, 1994).

A base desse processo verificado nos países capitalistas centrais deu-se nas pequenas propriedades camponesas, hoje denominadas propriedades de agricultura familiar. Isso foi em decorrência das alterações sofridas por essas estruturas produtivas em suas bases econômicas e sociais, afastando-se dos conceitos de Chayanov sobre o modo de produção camponês, o qual nunca se configurou enquanto modo de produção.

$\mathrm{Na}$ atualidade, pequena unidade de produção familiar não só está totalmente integrada ao mercado, constituindo-se numa importante peça-chave dentro dos cenários 
deste mercado, como também o seu modo de produção encontra-se altamente tecnificado e integrado aos diversos complexos agroindustriais existentes, ainda que se configurando como uma unidade de produção não capitalista.

\subsection{O caráter não capitalista da agricultura familiar}

A unidade de produção familiar configura-se hoje como unidade produtiva economicamente viável, acumulando e incorporando meios de produção, sem, ao mesmo tempo, criar relações sociais de produção antagônicas, que resultem na polarização entre trabalho e capital. Em resumo, a unidade de produção familiar tem conseguido capitalizar-se sem se tornar capitalista (MANN; DICKINSON, 1987).

Apesar dos pressupostos básicos da análise clássica de Marx e de seus seguidores terem sidos derrubados, através da sobrevivência da unidade de produção familiar, e, de certa forma, da demonstração de que esta se mostrou superior em relação à grande exploração capitalista, a explicação para a ocorrência desse processo foi justamente encontrada em Marx, nas relações entre tempo de trabalho e tempo de produção, conforme é destacado pelos autores Mann e Dickinson (1987).

O tempo de trabalho socialmente necessário para produzir uma mercadoria pode ser distinguido do tempo de produção gasto na produção de uma mercadoria, conforme Marx, apud Mann e Dickinson (1987, p. 15):

O tempo de trabalho é sempre tempo de produção, o que é o mesmo que dizer
que é um tempo durante o qual o capital é firmemente mantido na esfera de
produção. Mas o contrário não é verdadeiro, ou seja, nem todo o tempo em
que o capital é mantido no processo de produção é necessariamente tempo
de trabalho.

O tempo de produção consiste de duas partes: um período em que o trabalho é realmente aplicado na produção, e um segundo período, durante o qual a mercadoria "inacabada" é abandonada à influência de processos naturais, sem se submeter simultaneamente ao processo de trabalho, tendo, como exemplos, os processos naturais, químicos e fisiológicos. Enquanto o trabalho humano normalmente desencadeia esses processos, após o ponto de partida iniciado pelo insumo-trabalho, o processo prossegue de forma independente. Esses intervalos no processo de produção não criam nem valor e nem mais-valia, é o que ressaltam os autores Mann e Dickinson (1987).

A produção agrícola é caracterizada não somente por um relativo longo tempo de produção total (já que diversos cultivos são realizados anualmente), mas também por uma grande diferença entre o tempo de produção e o tempo de trabalho; há um longo período em que o tempo de trabalho é quase que completamente interrompido (exemplo disso, é o tempo em que a semente leva para se desenvolver na terra). Neste caso, a redução do tempo de produção é severamente afetada por fatores naturais e, assim, não pode ser facilmente modificada socialmente ou manipulada, como ocorre na indústria propriamente dita. Na produção pecuária, a reprodução dos animais é delimitada por processos naturais definidos.

Praticamente toda a pesquisa agrícola desenvolve esforços para reduzir a preponderância do tempo de produção sobre o tempo de trabalho: inseminação artificial, 
processos de alimentação forçada, desenvolvimento de sementes híbridas, cultivo de plantas em soluções nutritivas e outros. Por isso, a capitalização da agricultura avança mais rapidamente nas esferas onde o tempo de produção pode ser reduzido com sucesso. Inversamente, as esferas de produção caracterizadas por uma certa rigidez da não-identidade entre tempo de produção e tempo de trabalho não exercem a mesma atratividade ao grande capital, sendo deixadas, então, ao pequeno produtor familiar.

A não-identidade entre o tempo de produção e o tempo de trabalho estabelece uma série de obstáculos à penetração capitalista em certas esferas da agricultura, que, pelo fundamento biológico de seu processo produtivo, opõe resistência ao avanço da divisão social do trabalho, e, assim, ao próprio domínio da socialidade capitalista, comprometendo, no médio e longo prazo, a manutenção da taxa média de lucro do capital, já que este não consegue circular e se reproduzir de maneira mais rápida e eficaz, como ocorre na indústria (ABRAMOVAY, 1992).

Portanto, em razão dessas dificuldades, a grande propriedade produtora capitalista, na agricultura, cedeu espaço para a pequena unidade de produção familiar, pois esta última, preservando uma característica semelhante à das antigas unidades de produção camponesas, conseguiu se reproduzir com taxas de lucro abaixo da taxa média de lucro, porém com a utilização de instrumental produtivo altamente tecnificado e plenamente integrado ao mercado, competindo em igualdade de condições com a grande propriedade produtora capitalista, que, devido aos seus altos custos de manutenção e seu baixo e lento retorno dos investimentos de capital, retira-se da competição e, consequentemente, da produção agrícola.

Foi assim, então, que, nos países capitalistas centrais, coube à agricultura familiar o papel de grande produtora e fornecedora de alimentos e insumos para indústria, a preços mais baixos e em quantidade suficiente para garantir o abastecimento da população. Além disso, possibilitou a manutenção da renda dos agricultores familiares, colaborando para a fixação do produtor agrícola no campo, reduzindo significativamente o êxodo rural e melhorando as condições de trabalho e de vida, tanto campo como na cidade. Cabe ressaltar que coube ao Estado um papel extremamente importante, pois ele operou como elemento centralizador e responsável, em última análise, pela alocação da atividade dos agricultores.

Apesar da ocorrência dos fatos e acontecimentos levantados pelos diversos autores acima, na qual a preponderância da agricultura familiar, nos países capitalistas centrais, surgiu como fator decisivo para a derrocada de um dos pressupostos básicos de Marx e seus seguidores, que previam o fim da pequena unidade de produção camponesa, e, por conseguinte, da classe camponesa, e a preponderância da grande exploração capitalista, em decorrência do desenvolvimento do modo de produção capitalista, outros aspectos devem ser considerados na atual discussão.

O capitalismo configura-se como um modo de produção dinâmico e atuante no seu meio, e, dentro do debate estabelecido entre os autores clássicos e contemporâneos, outras contribuições para discussão se fazem necessárias, para o estabelecimento de novas e talvez melhores conceitualizações acerca do processo de penetração ou não do modo de produção capitalista na agricultura. 
Outra contribuição importante para o debate é trazida por Goodmann, Sorj e Wilkinson (1990), na qual, segundo estes autores, a industrialização da agricultura tomou um caminho diferente, determinado pelas limitações estruturais do processo de produção agrícola, representadas pela natureza enquanto conversão biológica de energia; tempo biológico no crescimento das plantas e na gestação animal; e espaço nas atividades rurais baseadas na terra. Incapazes de remover essas limitações diretamente, através da criação de um processo de produção unificado, os capitalistas industriais reagiram, adaptando-se às especificações da natureza na produção agrícola.

De acordo com esses autores, em decorrência da incapacidade do capital subjugar totalmente a agricultura, a sua industrialização vem ocorrendo de forma parcial, através dos processos de apropriação e de substituição. O processo de apropriação está associado, principalmente, ao processo de produção rural e com a transformação primária das safras, através de ligações com os capitais agroindustriais, e o complexo dos setores de equipamentos, processamento, sementes e agroquímico, onde as inovações mecânicas, químicas e, mais recentemente, genéticas fazem parte deste processo de apropriação.

Assim, para exemplificar, a partir do momento em que os capitais industriais retiraram a tração do arado puxado por cavalo, colocando em seu lugar um trator mecanizado; quando a fertilidade natural do solo foi industrializada através dos adubos químicos; quando as sementes naturais tiveram seu código genético alterado pela indústria; e outros exemplos, a agricultura estaria sendo apropriada pelos capitais industriais, ou seja, parcialmente industrializada.

Os capitais formados por apropriações parciais sucessivas dos processos de trabalho rural e de produção biológica são normalmente representadas pelo "complexo" agroindustrial, caracterizando-se pela dependência do fator terra. Porém, somente agora, com o surgimento das biotecnologias modernas, através das recombinações dos códigos genéticos, é que se tornou possível considerar a perspectiva de que o processo de transformação biológica poderá ser diretamente controlado pelos capitais industriais (GOODMANN; SORJ; WILKINSON, 1990).

O processo de substituição consiste na eliminação, pela indústria, da dependência dos insumos naturais oriundos da agricultura, ou seja, na substituição do processo rural de produção, seja pela utilização de matérias-primas não-agrícolas, seja pela criação de substitutos industriais dos alimentos e fibras. Seu paradigma, de acordo com os autores citados anteriormente, seria dado pela indústria química e pelo desenvolvimento dos sintéticos, portanto, assim, a natureza, seja enquanto terra, espaço ou reprodução biológica, não representaria mais uma limitação intransponível à transformação capitalista do processo de produção e da divisão social do trabalho.

As biotecnologias avançadas constituem a vanguarda desta ação tendencial rumo à dissolução da diferença entre agricultura e indústria. Estas formas de inovações estão por trás da rápida expansão dos produtos alimentícios industrializados e das chamadas comidas de conveniência, que estão ligadas diretamente à crescente complementaridade tecnológica entre as indústrias químicas, farmacêuticas e alimentícias. 


\section{A penetração do capitalismo na agricultura através dos Complexos Agroindustriais (CAIS)}

Apesar de estas abordagens contemporâneas conseguirem evidenciar determinados aspectos que não se configuraram nas previsões de Marx e de outros autores clássicos, a construção teórica de alguns autores contemporâneos permite, de maneiras diferenciadas, ou seja, alguns com maior ênfase, e outros com menor, distinguirem importantes traços de dominação do modo de produção capitalista na agricultura.

Para Goodmann, Sorj e Wilkinson (1990), o modo de produção capitalista penetra parcialmente na agricultura, pois atualmente se pode reproduzir apenas partes do processo da produção agrícola, mas, como não se consegue reproduzi-lo totalmente, não se pode ter um controle absoluto sobre esse processo (SILVA, 1998). Sendo assim, de acordo com Goodmann, Sorj e Wilkinson, apud Silva (1998), há uma continuidade na dependência da ação incontrolável da natureza, não se podendo falar num domínio completo do capital industrial na agricultura.

Apesar da abordagem dos autores Goodmann, Sorj e Wilkinson (1990) afirmar que o processo de industrialização da agricultura é parcial, permite concluir que o modo de produção capitalista continua a lutar para derrubar os últimos obstáculos que lhe são erguidos na agricultura, como bem ressaltam os autores Mann e Dickinson (1987), na questão da diferença entre tempo de trabalho e tempo de produção.

Entretanto, através da abordagem de Silva (1996), quando o autor relata a crise do complexo rural e sua passagem aos Complexos Aagroindustriais (CAIs), em seus estudos sobre o comportamento do modo de produção capitalista no Brasil, ele ressalta que este processo acabou culminando na industrialização da agricultura e sua consequente submissão ao capital representado pelos interesses dos diversos setores industriais ligados à produção agrícola.

Conforme Silva (1996), o complexo rural foi caracterizado pelas fazendas do Brasil Colonial, nas quais havia uma divisão do trabalho bastante incipiente e onde eram produzidos todos os bens intermediários e os meios de produção necessários utilizados no processo produtivo, além de buscar assegurar a reprodução da mão-de-obra necessária para o trabalho, que normalmente era constituída de escravos.

A crise do complexo rural começou em 1850, com a proibição do tráfico de escravos, e levou ao surgimento do novo complexo cafeeiro paulista; ao mesmo tempo em que propiciou um processo de substituição de importações, significou o desenvolvimento do mercado de trabalho e a constituição do mercado interno, acelerando-se com a crise de 1929, direcionando a economia no sentido da industrialização que se consolidou nos anos 1950, com a internalização do setor industrial produtor de bens de capital e insumos básicos - D1 (departamento no 1, designação dada por Marx ao setor produtor de meios de produção, aprimorado mais tarde por Michal Kalecki).

Desse momento em diante, completou-se a industrialização de maneira geral, e se iniciou o processo específico de industrialização da agricultura, com a montagem de um D1 agrícola e de um proletariado rural, que iriam responder pelo fornecimento de capital e trabalho, dentro da nova dinâmica de acumulação de capital no campo, onde a indústria e as demandas oriundas das populações urbanas condicionaram as transfor- 
mações na agricultura, que conduziram ao domínio dos complexos agroindustriais.

Assim, em decorrência das especificidades do caso brasileiro, através do desenvolvimento de um mercado interno, com a industrialização da agricultura, via passagem do complexo rural aos complexos agroindustriais - CAls, pode-se verificar que na dispersão daquele conjunto intricado de atividades internalizadas nas fazendas coloniais, que se urbanizaram e se industrializaram gradativamente, forçadas pela constituição de novos ramos da produção; e, depois, num segundo momento, quando o parque industrial brasileiro se completou com a internalização do D1 da agricultura, nos anos 1960 e 1970, ocorreu uma convergência de atividades afins, por força da própria especialização dos novos ramos que foram se constituindo dentro e fora da própria agricultura, criando laços indissolúveis entre elas, só que agora fora das fazendas (SILVA, 1998).

Dessa maneira, a constituição dos vários complexos agroindustriais privilegiou a inter-relação entre os diversos ramos da demanda final e aqueles setores produtores de insumos e meios de produção específicos para um determinado produto de origem agrícola, constituindo-se, assim, o CAl carnes, o CAI laranja, o CAl soja e outros tantos. Porém o que cabe destacar é a internalização do D1, pois, com a implantação no Brasil das indústrias químicas e mecânicas, fabricantes de insumos e máquinas agrícolas é que foi possível aprofundar o processo de modernização com a industrialização da agricultura e a constituição dos vários CAls (SILVA, 1998).

Portanto, através da abordagem de Silva (1998), pode-se constatar a penetração do modo de produção capitalista na agricultura, com a industrialização desta, decorrente da constituição dos vários CAls, ligados a ela, confirmando a previsão de Marx de que um elemento fundamental do desenvolvimento do capitalismo era a criação do mercado interno, ou seja, o desenvolvimento da produção mercantil, através da divisão social do trabalho, tendo como apoio, para a penetração deste na agricultura, a separação dos diferentes processos de transformação das matérias-primas, que eram retiradas, uma a uma, da agricultura, para, posteriormente, transformarem-se em ramos industriais com vida própria, retornando a relacionar-se com a agricultura, através da venda de mercadorias, trocando seus produtos por produtos da agricultura.

\section{Conclusão}

O breve debate entre os autores clássicos e contemporâneos contribuiu para elucidar diversas questões pertinentes às relações entre o modo de produção capitalista e a agricultura.

Por um lado, o debate possibilitou a verificação de que nem todas as previsões elaboradas por Marx e seus seguidores, como Kaustky e Lênin, ocorreram. Não houve a supremacia da grande exploração capitalista, em relação à pequena unidade produtora camponesa nem o consequente desaparecimento da classe camponesa. Ocorreu justamente o contrário, ou seja, a derrocada, nos países capitalistas centrais, das grandes propriedades capitalistas, que cederam lugar à eficiente pequena unidade produtora familiar.

Contudo, de outro lado, também é plenamente verificável, confirmando as previsões de Marx e as dos demais autores marxistas, que o modo de produção capitalista, 
através da industrialização dentro da lógica dos CAls - tanto no Brasil como nos países capitalistas centrais -, conseguiu penetrar na agricultura e impor sua sistemática de produção, apesar de haver concordância em que a unidade produtora familiar não constitui uma estrutura produtiva capitalista e que a questão relativa ao tempo de trabalho e tempo de produção ainda não tenha sido resolvida pelo sistema capitalista.

Mesmo assim, o modo de produção capitalista não tem medido esforços em substituir ou apropriar-se de processos naturais de produção, onde a natureza dita as regras do desenvolvimento de plantas e animais, trocando-os por artificiais. Para isso, conta com uma gama enorme investimentos feitos por grandes grupos econômicos e segmentos públicos nas áreas da mecânica, química e biotecnologia, a fim de reduzir e, se possível, eliminar os entraves postos pela natureza ao completo domínio pelo modo de produção capitalista do processo produtivo na agricultura.

Por fim, cabe destacar que, mesmo tendo algumas de suas previsões não verificadas atualmente, Marx demonstra, ainda, uma grande vitalidade no seu discurso, pois a penetração do modo de produção capitalista na agricultura, através da industrialização desta, nas suas relações com os complexos agroindustriais, somente foi verificável à luz das teorias desenvolvidas por ele.

Portanto, as conclusões que emergem deste artigo, apesar de esclarecerem muitas questões, não tornam este trabalho um fim em si mesmo, pois propiciam e instigam outras pesquisas sobre o assunto. Isso porque o modo de produção capitalista, guardadas as devidas proporções e as argumentações em contrário, vem buscando, cada vez mais, impor-se perante a agricultura, subjugando-a através de sua efetiva industrialização, promovendo a penetração do capitalismo nas relações sociais e produtivas do campo.

\section{Referências}

ABRAMOVAY, Ricardo. Paradigmas do capitalismo agrário em questão. São Paulo: Hucitec, 1992.

BOTTOMORE, Tom. Dicionário do pensamento marxista. Rio de Janeiro: Jorge Zahar, 1988.

FONSECA, Rinaldo Barcia. A reforma das políticas agrícolas dos países desenvolvidos. 1994. Tese (Doutorado em Economia) - Universidade Estadual de Campinas, Campinas, 1994.

FREITAS, Eduardo de; ALMEIDA, J. Ferreira de; CABRAL, M. Villaverde. Modalidade de penetração do capitalismo na agricultura. Estruturas agrárias em Portugal continental, 1950 - 1970. Lisboa: Editorial Presença, 1976.

GOODMANN, David; SORJ, Bernardo; WILKINSON, John. Da lavoura às biotecnologias - agricultura e indústria no sistema internacional. Rio de Janeiro: Campus, 1990. 
KAUTSKY, Karl. A Questão Agrária. Rio de Janeiro: Laemmert, 1968.

LÊNIN, V. I. Aos pobres do campo. São Paulo: Acadêmica, 1988.

MANN, Susan A.; DICKINSON, James M. Obstáculos ao Desenvolvimento da Agricultura Capitalista. Literatura econômica, Rio de Janeiro, IPEA, n. 1, v. 9, p. 7-26 fev. 1987.

MARX, Karl. O capital - crítica da economia política. 14. ed. Rio de Janeiro: Bertrand Brasil, v. 1, v. 2. 1994.

SANDRONI, Paulo. Novo dicionário de economia. São Paulo: Best Seller, 1994.

SILVA, José Graziano da. A nova dinâmica da agricultura brasileira. Campinas: Unicamp, 1996.

2. ed. Campinas: Unicamp, 1998.

O progresso técnico e relações de trabalho na agricultura. São Paulo: Hucitec, 1981.

VEIGA, José Eli da. Desenvolvimento agrícola: uma visão histórica. São Paulo:

EDUSP/HUCITEC, 1991.

Fundamentos do agrorreformismo. In: STÉDILE, João Pedro (Coord.). A questão

agrária hoje. 2. ed. Porto Alegre: UFRGS, 1994. p. 68-93. 